\title{
Preliminary objective regionalization of the Mediterranean basin derived from surface-wave tomography
}

\author{
M. Dolores Martínez $\left({ }^{1}\right)$, Xavier Lana $\left({ }^{2}\right)$, José Badal $\left({ }^{3}\right)$, J. Antonio Canas $\left({ }^{4}\right)$ and Lluis Pujades $\left({ }^{4}\right)$ \\ $\left.{ }^{1}\right)$ Departament de Física Aplicada, Universitat Politècnica de Catalunya, ETSAB, Barcelona, Spain \\ ${ }^{(2)}$ Departament de Física i Enginyeria Nuclear, Universitat Politècnica de Catalunya, \\ ETSEIB, Barcelona, Spain \\ $\left(^{3}\right)$ Departamento de Física Teórica-Geofisica, Universidad de Zaragoza, Zaragoza, Spain \\ $\left({ }^{4}\right)$ Departament d'Enginyeria del Terreny, Universitat Politècnica de Catalunya, \\ ETSECCPB, Barcelona, Spain
}

\begin{abstract}
An objective regionalization of the Mediterranean basin is derived from a tomographic study based on the fundamental mode of Rayleigh waves. The database is formed by seismic wavetrains recorded at very-broadband stations belonging to MEDNET and other cooperative stations, located in the Mediterranean area. The data treatment consists of application of spectral filtering techniques aimed to determine path-averaged group velocities, computation of local group velocity maps for some periods and classification of the studied area in algorithms. Finally, the group velocity dio Principal Component Analysis (PCA) and Average Linkage (AL) and possible correlation between these regions curves representing each homogeneous region are compared cussed.
\end{abstract}

Key words Mediterranean basin - Rayleigh waves - local group velocities - clustering algorithms

\section{Introduction}

The set of regional and teleseismic events recorded from 1990 to 1993 at very-broadband stations belonging to MEDNET (Giardini et al., 1992) and other cooperative networks, located in the Mediterranean area (fig. 1), supplies a database to attempt a complete surface wave tomographic study of the Mediterranean basin,

Mailing address: Dr. M. Dolores Martínez, Departament de Física Aplicada, Universitat Politècnica de Catalunya, ETSAB, Avenida Diagonal 649, 08028 Barcelona, Spain; e-mail: MARTINEZ@FA.UPC.ES aimed at improving the knowledge of the elastic and anelastic structure of the crust and upper mantle in this region.

Whereas the teleseismic events will contribute in the future to improve this knowledge, we focus at present on Rayleigh wave fundamental mode group velocities derived from regional events. Figure 2 shows the potential epicentre-station paths corresponding to regional events of the period 1990-1993 with surfacewave magnitudes between 4.5 and 6.5. The study is specially aimed at obtaining an objective regionalization of the Mediterranean basin in terms of local group velocity maps for periods ranging from $10 \mathrm{~s}$ to $60 \mathrm{~s}$. This regionalization is obtained without any a priori seismotectonic or structural constraint and characteristics related to the different homogeneous regions obtained are also discussed. 


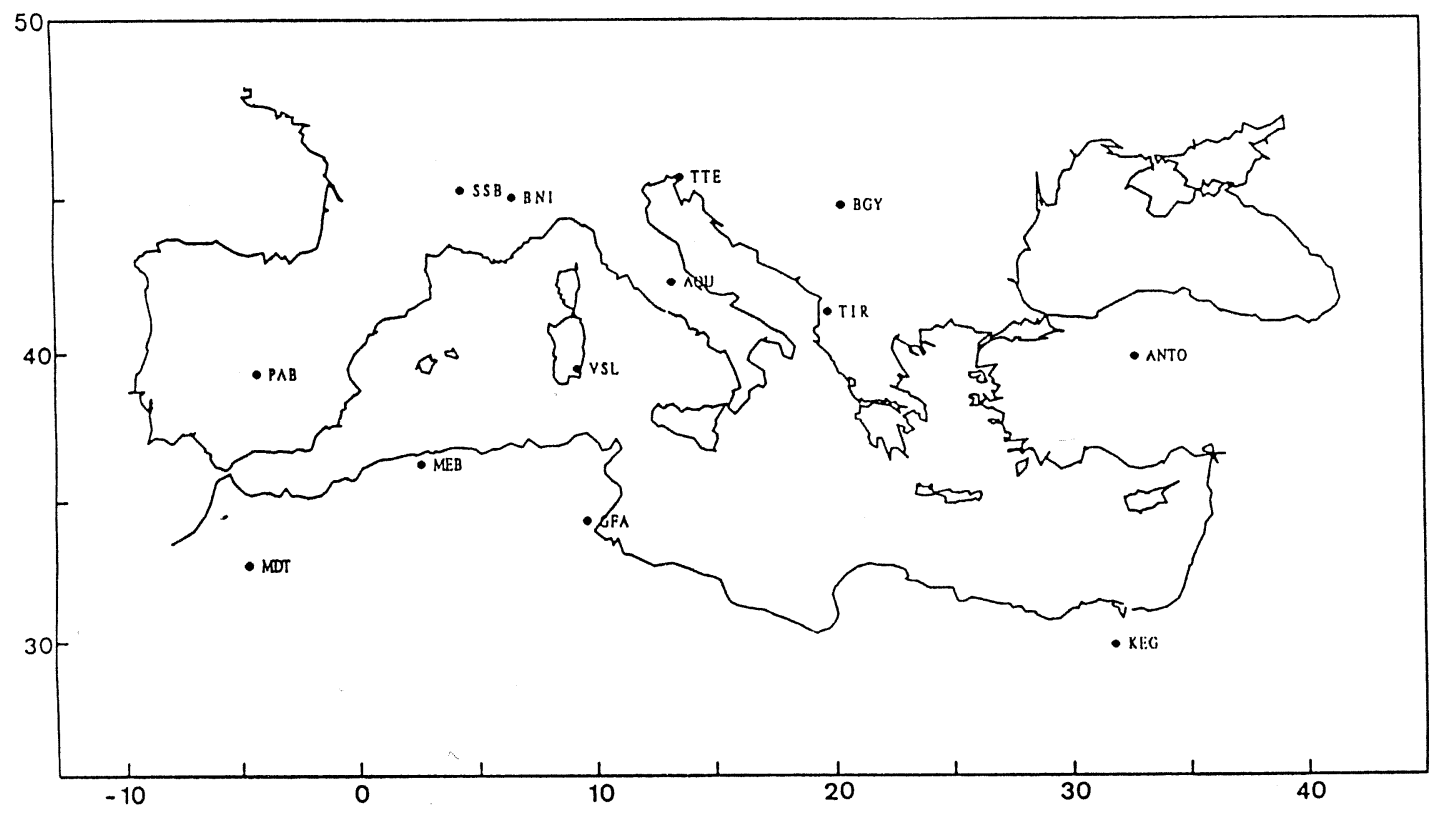

Fig. 1. Location of broadband stations belonging to the MEDNET and other cooperative stations located in the Mediterranean region.

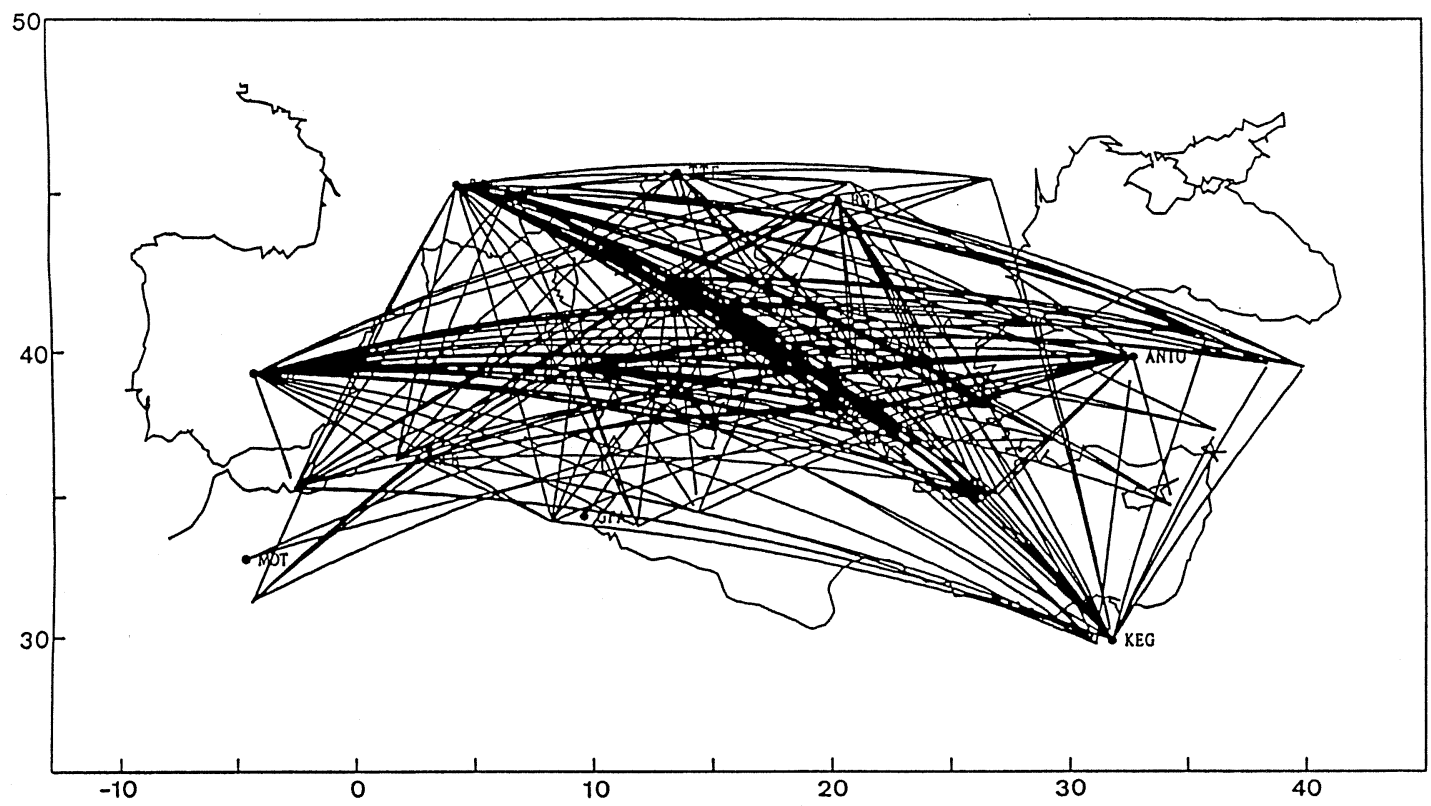

Fig. 2. Potential epicentre-station paths corresponding to regional events of the period 1990-1993 with surface-wave magnitudes between 4.5 and 6.5 . 


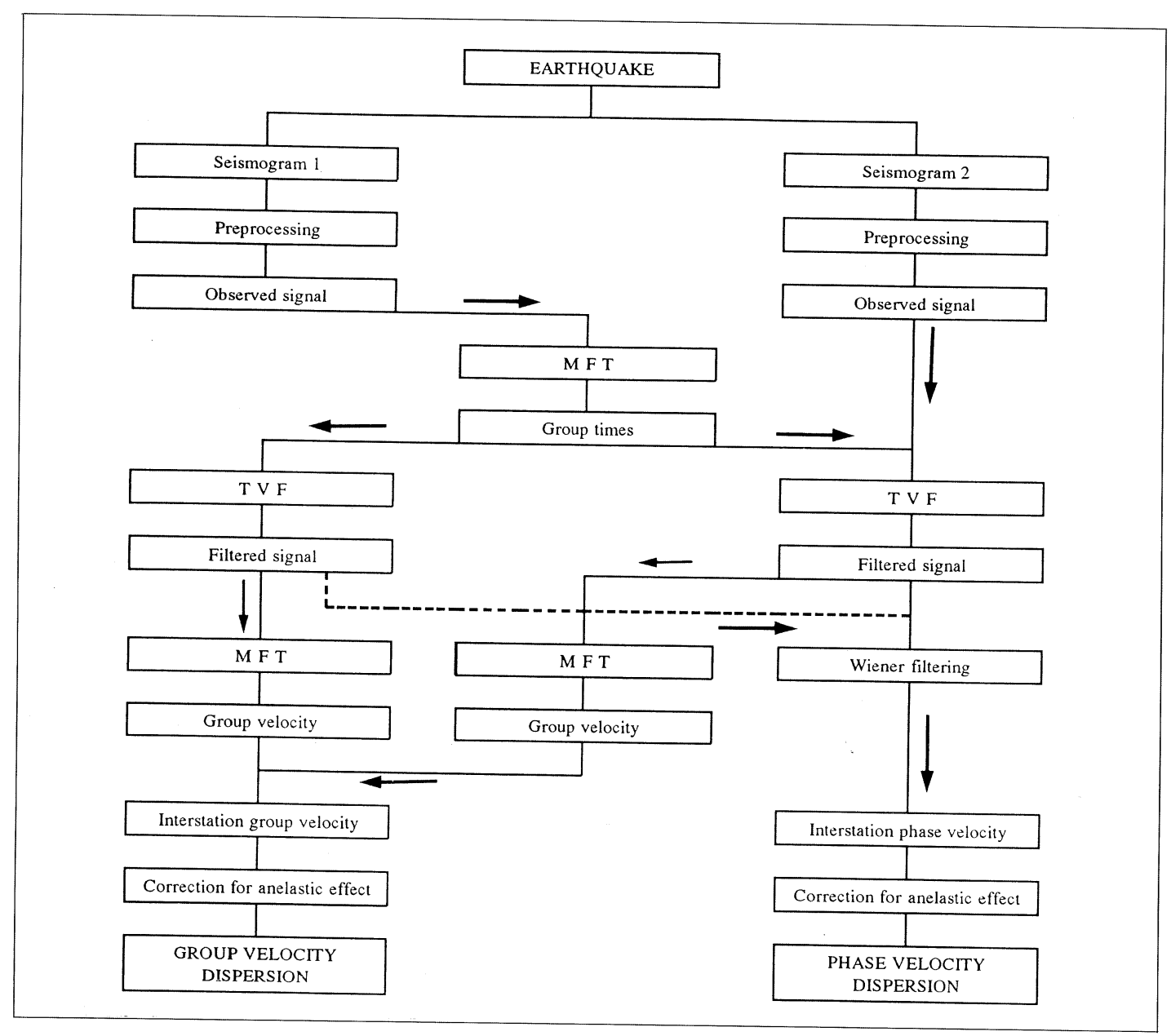

Fig. 3. Schematic description of the filtering processes leading to path averaged phase and group velocities for epicentre-station trajectories and for trajectories between pairs of stations along the same great circle connecting with the epicentre.

Figure 3 shows the process leading to the determination of empirical path averaged phase and group velocities, by means of a sequential application of different filtering techniques: Multiple Filtering (MFT), Time Variable Filtering (TVF) and Wiener deconvolution. Empirical path averaged attenuation coefficients can be easily obtained by simply applying MFT. A better understanding of the global objectives concerning the analysis of teleseismic and re- gional events is shown in fig. 4 which describes procedures for obtaining elastic structures from surface-wave dispersion data. The same scheme applies to attenuation coefficients.

The procedure leading to the regionalization of the studied area is the same as that used by Lana et al. (1997) on a tomographic study of the Iberian peninsula. According to figs. 3 and 4, this procedure consists of: 1) filtering of 


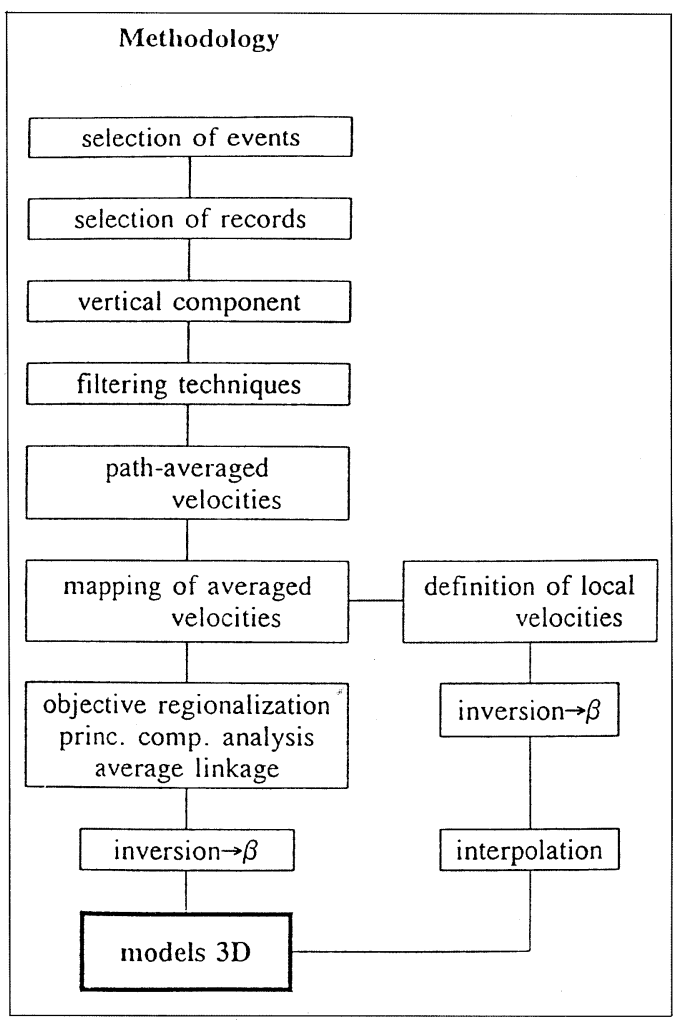

Fig. 4. Schematic description of the methodology leading to three-dimensional elastic and anelastic structures.

the seismic wavetrains and evaluating the corresponding path-averaged group velocities; 2) mapping of local group velocities at several periods on the basis of the above mentioned averaged velocities; 3) classification of the area in several homogeneous regions by means of the Principal Component Analysis (PCA) and Average Linkage (AL) algorithms; 4) computation of group velocity dispersion curves related to each homogeneous region and discussion of possible correlations among the different regions and seismotectonic characteristics. Each of these points is developed and discussed in the following sections.

In short, the mapping and regionalization process shown at present establishes the basis for a detailed exploration of the shear velocity struc- ture of the Mediterranean basin from the viewpoint of surface-wave tomography and for a posterior comparison with crust and upper mantle models obtained by body wave tomography.

\section{Filtering process}

The first step of the data treatment consists of the application of spectral filtering techniques to each seismic record to isolate the fundamental mode of Rayleigh waves and, posteriorly, to compute path averaged group velocities. The most usual filtering procedure is the Multiple Filtering Technique (MFT) (Dziewonski and Hales, 1972; Herrmann, 1973) which directly gives us averaged group velocities for each epicentre-station path. A refinement of this process can be obtained by the sequential application of MFT, TVF (Cara, 1973) and again MFT. Although the discrepancies on group velocities obtained by both methods use to be almost negligible, the sequential application of the filtering techniques tends to enlarge the period range of empirical group velocities.

This aspect is illustrated in fig. 5, where the dispersion curve corresponding to a wavetrain recorded at the station VSL is shown. The epicentre is located at $40.87^{\circ} \mathrm{N}$ and $28.88^{\circ} \mathrm{E}$, the epicentral distance is $1664.9 \mathrm{~km}$ and the $M_{S}$ magnitude is 5.9. By applying MFT empirical group velocities (open squares) up to $58 \mathrm{~s}$ are obtained. By sequential application of MFT, TVF and again MFT, the dispersion curve obtained (solid line) provides reliable group velocities up to $70 \mathrm{~s}$. Figure $6 \mathrm{a}, \mathrm{b}$ depicts a part of the seismic wavetrain, corrected by the instrumental response, (a) before and (b) after the filtering process. One may observe the well defined surface wavetrain of the fundamental mode with peaks and troughs coinciding with the original record and the suppression of the high frequency component by the filtering process.

In spite of the good quality of the database, a non negligible number of records were discarded after the filtering process due to some unrealistic group velocity values obtained. With respect to the period range, in some cases, the sequential application of the filtering 


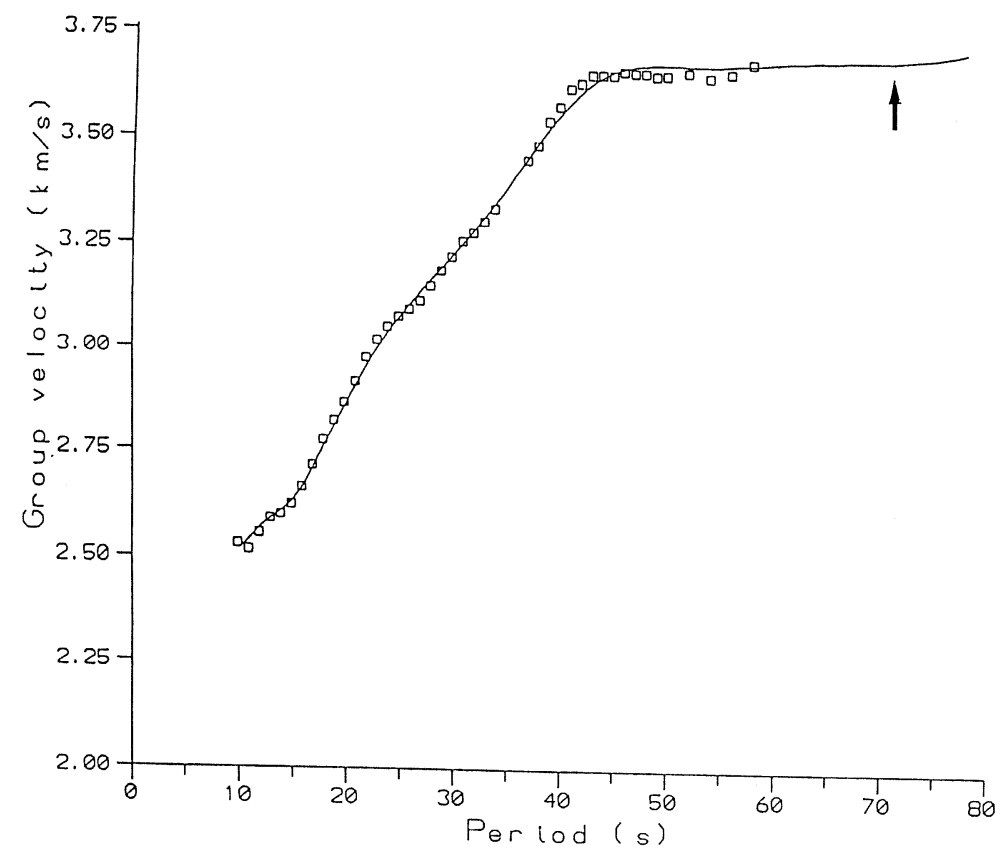

Fig. 5. Path-averaged group velocities for a wavetrain recorded by station VSL. Velocities obtained by applying MFT and the sequential MFT, TVF and MFT are designed by open squares and the solid line, respec-
tively.

(a)

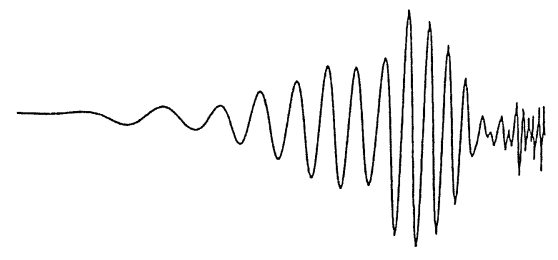

(b)
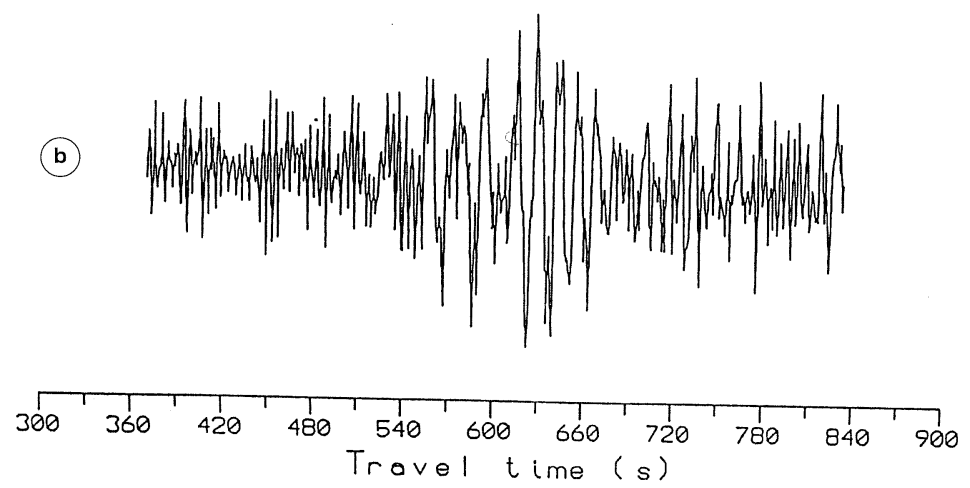

Fig. 6a,b. a) Surface wavetrain corrected by instrumental response; b) filtered waveform corresponding to the
Rayleigh wave fundamental mode. 
techniques gives us velocity values for the $5-80 \mathrm{~s}$ period range. Nevertheless, only for the $10-60 \mathrm{~s}$ period range is the path coverage almost the same. We have to bear in mind that at short periods (less than about $10 \mathrm{~s}$ ) it is difficult to isolate the surface-wave fundamental mode. In addition, depending on the epicentral distance, not all the analyzed records can give information for long periods. Consequently, the computation of local velocity maps was made for 46 different periods ranging from 10 to $60 \mathrm{~s}$.

\section{Mapping of local velocities}

The computation of maps of local group velocities for the different periods analyzed has been extensively studied for many years, the use of spherical harmonic functions being a very common procedure to describe local group velocities in terms of latitude and longitude. This method is especially indicated in studies concerning the whole Earth's surface (Sato and Santo, 1969; Nakanishi and Anderson, 1982; Dziewonski, 1984) but it has also been applied to parts of the Earth's surface as the Indian ocean (Lana and Carbonell, 1987). The effects of Gibbs' phenomena on the resulting maps have to be carefully taken into account in these cases. If we try to map smaller regions, the above mentioned phenomena can absolutely distort the maps obtained and spherical harmonic developments have to be discarded in these cases. A possible solution comes from the Backus-Gilbert formulation (Backus and Gilbert, 1968; Backus and Gilbert, 1970) and Yanovskaya's methodology (Yanovskaya, 1984) that have been successfully applied, for instance, to tomographic studies for the Iberian peninsula (Nikolova et al., 1996).

Following the approximation of geometrical optics, we can express the Epicentre (E) - Station (S) group travel time, $t_{i}$, empirically deduced in terms of the quotient between the epicentral distance and the path-averaged group velocity, as

$$
t_{i} \int_{E}^{S} V(x, y)^{-1} d s
$$

where $d s$ is a differential element of the seis- mic path and $V(x, y)$ is an unknown function describing the local group velocity. If we assume a preliminary function describing the local group velocities, $V_{0}$, the problem is reduced to determine

$$
m(x, y)=\frac{\delta V(x, y)}{V_{0}}
$$

where $\delta V(x, y)$ are the unknown variations on $V_{0}$. According to the Backus-Gilbert approach, the expected value of $m(x, y)$ will be the linear combination

$$
E[m(x, y)]=\sum_{i} a_{i}(x, y) \delta t_{i}
$$

where $a_{i}$ are some unknown functions and $\delta t_{i}$ the discrepancies between the experimental travel time and the time corresponding to the starting model $V_{0}$. This unknown function is related to the data kernels, $G_{i}$, and the averaging function, $A$, by means of

$$
\sum_{i} a_{i}\left(x_{0}, y_{0}\right) G_{i}\left(x, y, x_{0}, y_{0}\right)=A\left(x, y, x_{0} y_{0}\right) .
$$

The functions $a_{i}$ have to be determined under the constraint that the corresponding averaging function $A$ must be as close as possible to a delta function. On this way, according to

$$
E\left[m\left(x_{0}, y_{0}\right)\right]=\int_{x} \int_{y} m(x, y) A\left(x, y, x_{0}, y_{0}\right) d x d y
$$

the expected value of $m(x, y)$ will be very close to the real unknown $m(x, y)$. According to Nikolova et al. (1996), the closer $A\left(x, y, x_{0}, y_{0}\right)$ is to a delta function, the smaller the resolving power value of a point of coordinates $\left(x_{0}, y_{0}\right)$. Consequently, great resolving values are related to poorly solved local velocities and they strongly depend on velocities of the neighbouring points. On the contrary, small resolving values are linked to well solved velocities, which will be almost independent of the neighbouring values. 


\section{Objective regionalization}

Algorithms devoted to objective regionalization (Kalkstein et al., 1987; Fernández Mills et al., 1994; Periago et al., 1991) are very common in climatology, but they are not so usual in seismology. Some examples of seismotectonic or tomographic applications can be found in Lana and Fernández Mills (1992) or Lana et al. (1997). A common regionalization method applied to tomographic problems has been the «pure-path» method or combination of spherical harmonic developments and «pure-path» method ( $\mathrm{Yu}$ and Mitchell, 1979; Nishimura and Forsyth, 1985). The latter method could be useful for domains including oceanic ridges and neighbouring areas where a preliminary division in terms of structural crustal age is reasonable. Nevertheless, for other kind of regions as continental domains or small basins, it is much more difficult to use correctly a priori seismotectonic and structural information with the aim of obtaining a regionalization. A possible solution in these cases comes from an objective regionalization made only in terms of the tomographic results and a quest for possible correlation among the seismotectonic available data and the regions obtained.

The first algorithm used in the present study is the Principal Component Analysis (PCA) (Preisendorfer, 1988)) that simplifies the classification and removes redundancies among the different variables to be classified (local group velocities for different periods). Some applications of this procedure can be found in seismology (Michelini and Bolt, 1986; Posadas et al., 1993) mainly devoted to seismotectonic aspects. The procedure is based on computation of eigenvalues and eigenvectors of the data covariance matrix, $\boldsymbol{C}$, which represents covariances among all the different periods analyzed.

From now on, the original variables (46 periods) are substituted by the most relevant Principal Components (PC) which are computed by

$$
\begin{gathered}
\boldsymbol{X}=\boldsymbol{A} \boldsymbol{Y} \\
\boldsymbol{A}=\boldsymbol{V} \boldsymbol{D}^{1 / 2}
\end{gathered}
$$

where $\boldsymbol{X}$ represents the original variables, $\boldsymbol{Y}$ the principal components, $\mathbf{A}$ is the factor loading matrix, $\boldsymbol{V}$ the eigenvector matrix and $\boldsymbol{D}$ the diagonal eigenvalue matrix. Remembering that each PC explains a percentage of data variance, the usual procedure is to consider only components related to eigenvalues greater than 1 , or in other words, components explaining at least as variance as an original variable. Taking into account that another problem is the possibility of computing degenerated eigenvalues (North et al., 1992), the usual solution is to choose only PC related to non-degenerated eigenvalues greater than 1 (Fernández Mills and Lana, 1994).

The regionalization process is made according to the Average Linkage (AL) algorithm (Kalkstein et al., 1987). At the beginning of the process, each point of the domain is an homogeneous region. In each step of the algorithm, we have to search for all possible pairs to be fused, choosing the fusion linked to the minimum value of a similarity index $L_{i j}$, given by

$$
L_{i j}=D_{i j}^{2}+V_{i}+V_{j}
$$

and computed in terms of PC values, where $D_{i j}$ is the distance between centroids of regions $i$ and $j, V_{i}$ and $V_{j}$ are the intragroup variances. If we repeated the process of fusion indefinitely without other criteria, we would arrive at a useless solution with all the points classified in a single region. Nevertheless, looking at the evolution of the minimum value of $L_{i j}$ for each step, when a sharp increase of this index is detected, we can assume that the algorithm attempts to merge to very dissimilar areas. The best configuration of homogeneous areas will be then the one corresponding to the last attempted fusion before the sharp change.

\section{Application}

The Mediterranean area is included in a quite complex plate boundary between Eurasia and Africa. As a general pattern, the region is made up of blocks trapped between both plates, with the seismicity governed by the 


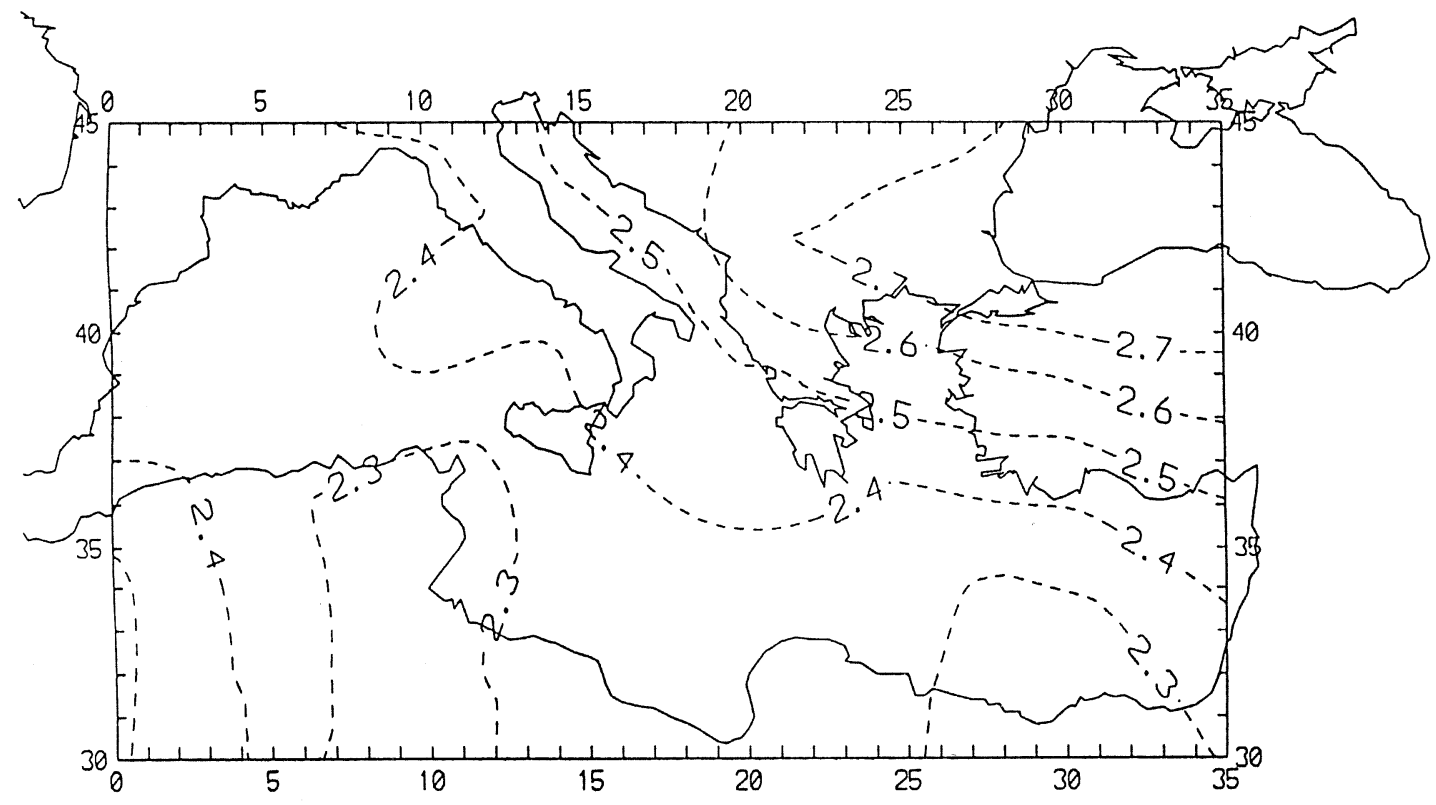

Fig. 7a. Map of local group velocity $(\mathrm{km} / \mathrm{s})$ for $10 \mathrm{~s}$.

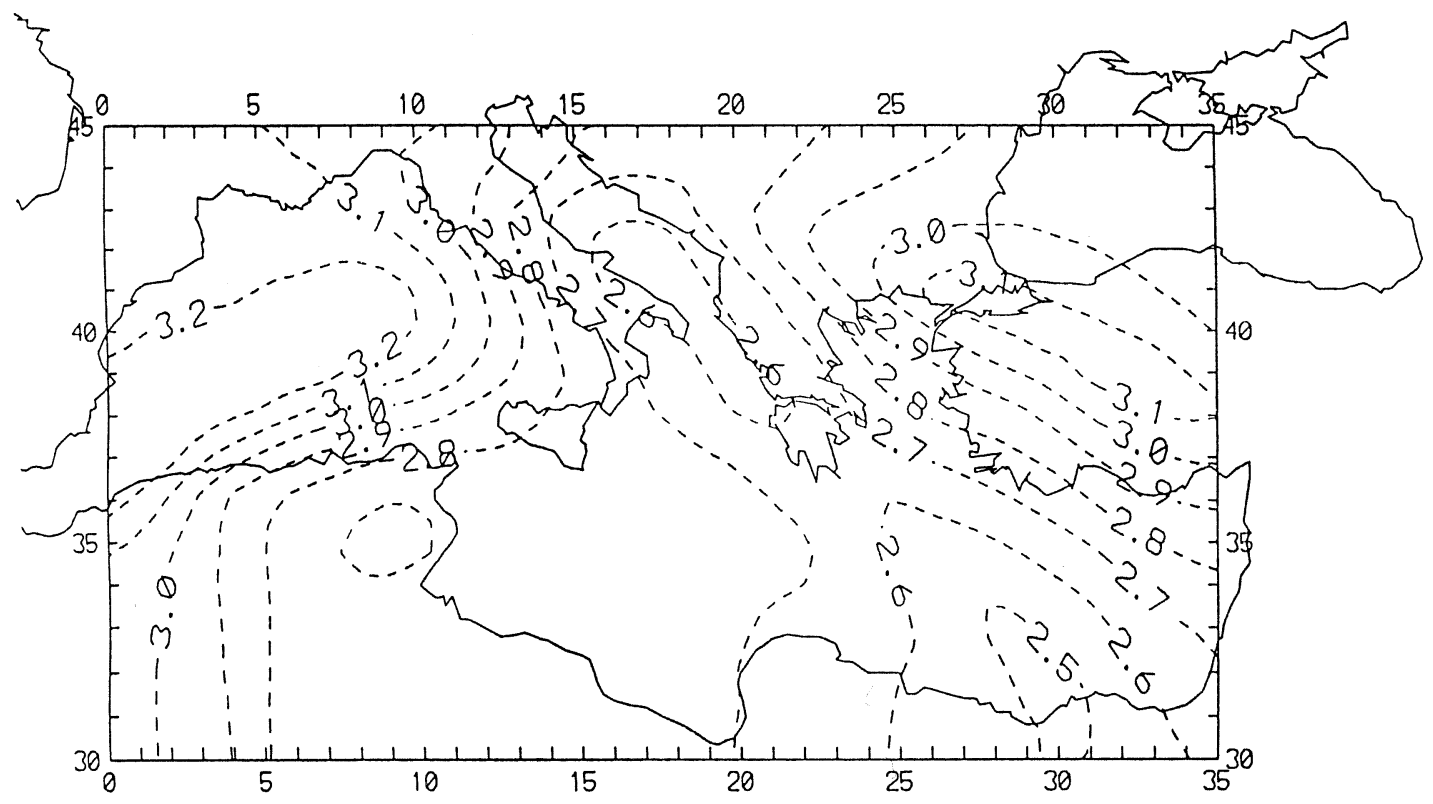

Fig. 7b. Map of local group velocity $(\mathrm{km} / \mathrm{s})$ for $20 \mathrm{~s}$. 


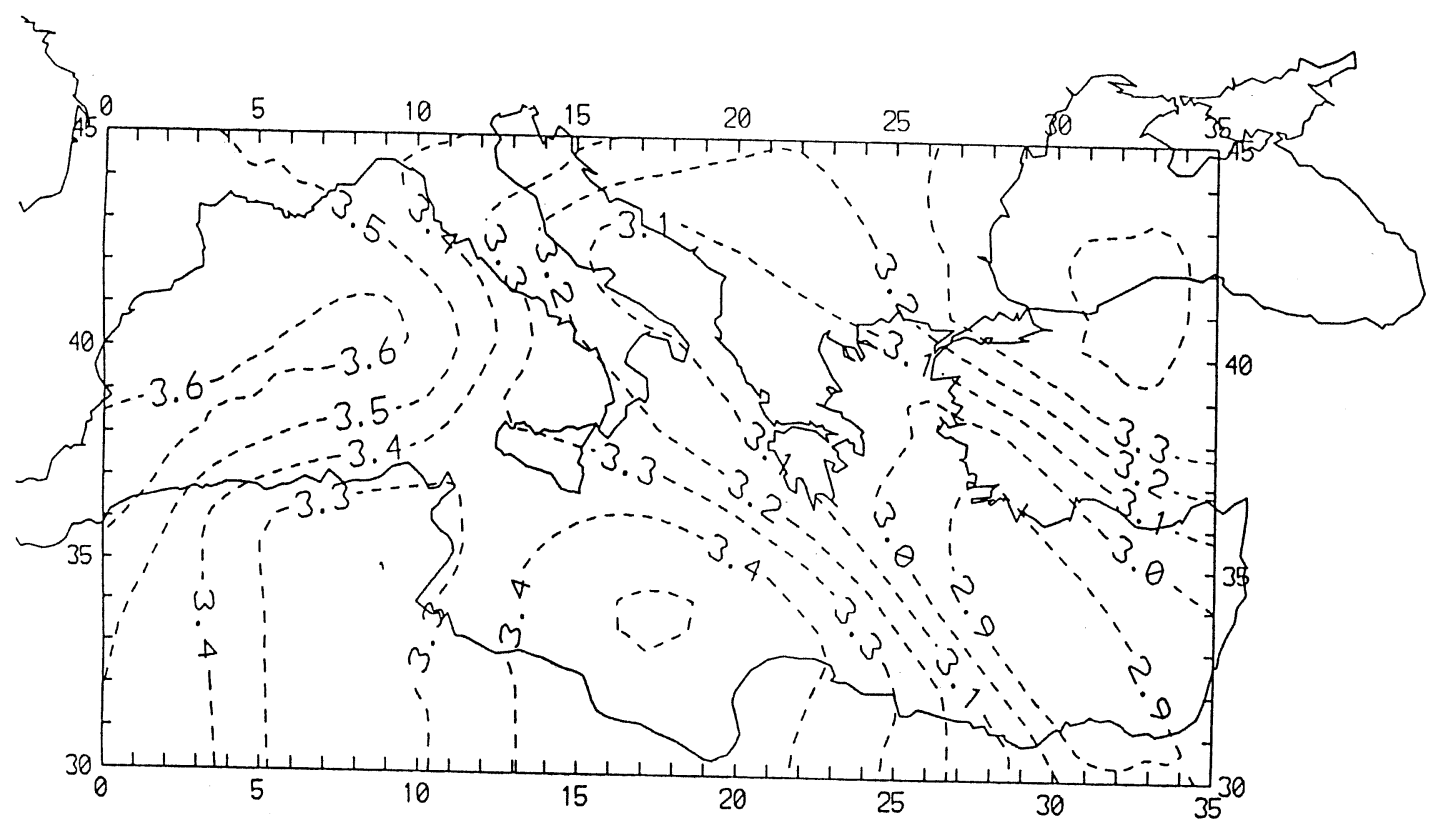

Fig. 7c. Map of local group velocity $(\mathrm{km} / \mathrm{s})$ for $30 \mathrm{~s}$.

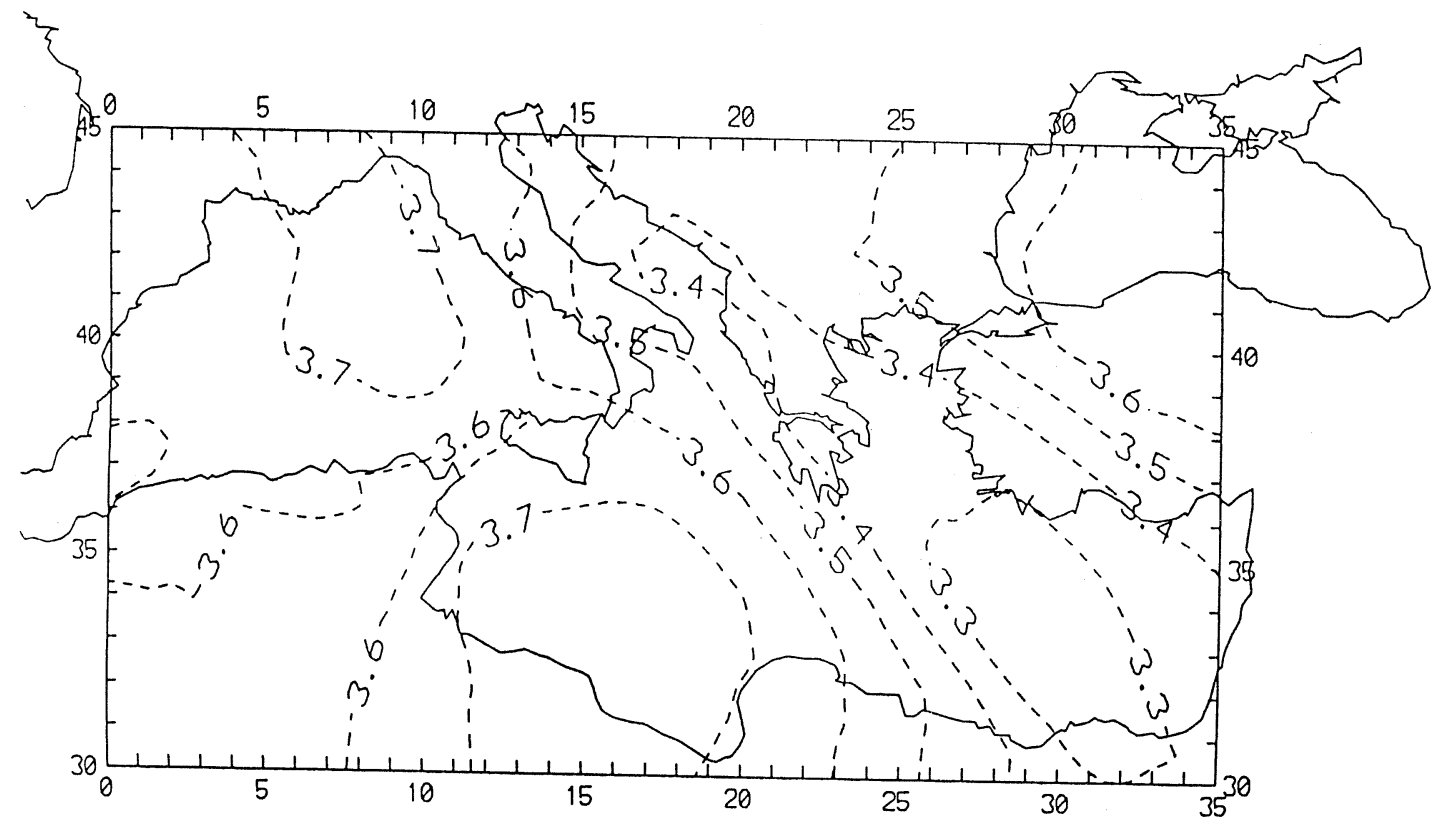

Fig. 7d. Map of local group velocity $(\mathrm{km} / \mathrm{s})$ for $40 \mathrm{~s}$. 


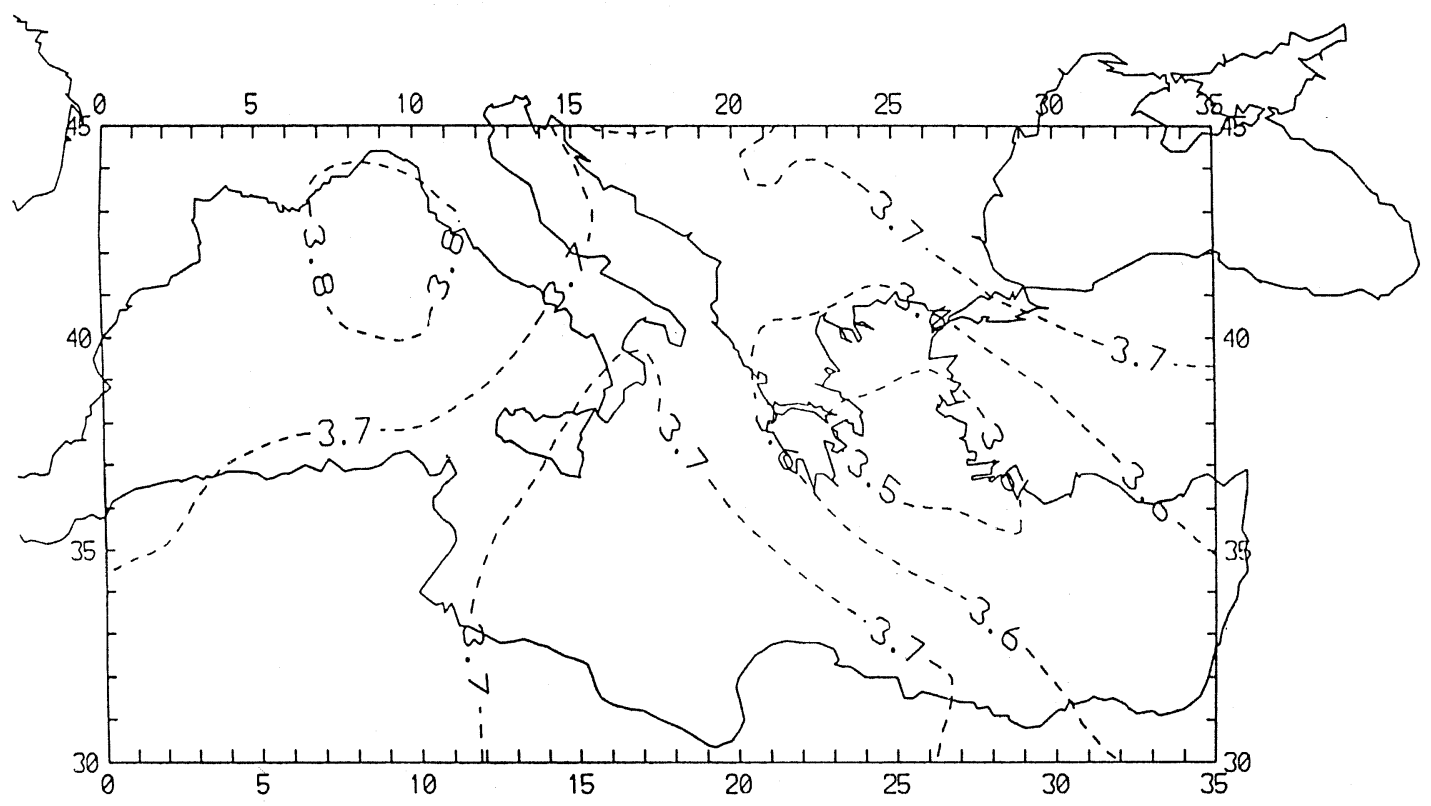

Fig. 7e. Map of local group velocity $(\mathrm{km} / \mathrm{s})$ for $50 \mathrm{~s}$.

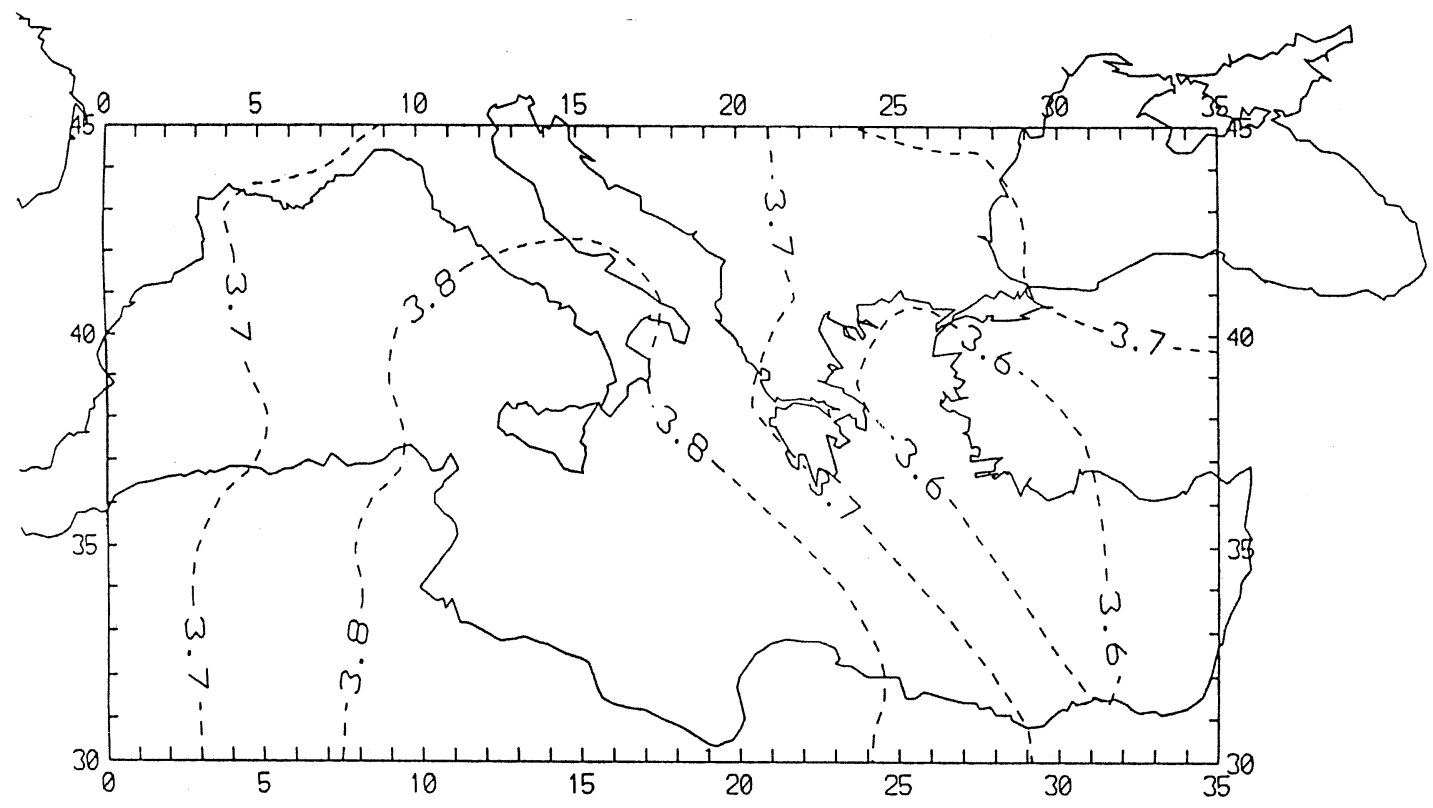

Fig. 7f. Map of local group velocity $(\mathrm{km} / \mathrm{s})$ for $60 \mathrm{~s}$. 
convergence of them and with predominance of subduction (Aegean arc, Calabrian arc) and collision (Alps) mechanisms. Intermediate cases from subduction to collision, as the Apenninic chain or the Betic Cordillera, also have to be considered. The seismic activity is mainly concentrated towards the East (Aegean arc), but it is also remarkable in the Alps, the Italian peninsula, North Africa, Alboran sea and Adriatic area. A lower seismic activity is detected on Southern Spain, linked to the Betic system. A classic detailed revision of the seismotectonics of the region can be found, for instance, in McKenzie (1972), and a more recent tectonic description is given by Philip (1988). Examples of transition from subduction to collision are given by Bousquet and Philip (1986).

A previous classification of the region in terms of seismotectonic characteristics would be difficult. First of all, we must stress that the relatively simple description cited here does not take into consideration more detailed tectonic characteristics. On the other hand, the shallowest elastic structure of the Mediterranean basin can present small scale changes. As an example, whereas Corsica, Sardinia, Tunisia (Banda et al., 1985), the North Balearic basin (Banda et al., 1980), the Alboran sea (Hatzfeld, 1978) and the Sardinia channel (Martínez and Lana, 1991) have a continental character, very close zones as the Ligurian sea (Finetti and Morelli, 1973) and the Southern Balearic basin (Banda et al., 1980) have an oceanic structure. We also have to remember that for the range of analyzed periods the corresponding local group velocity curves are modelled by elastic structures with depths clearly exceeding the Moho discontinuity and reaching up to $150-200 \mathrm{~km}$. Consequently, to attempt an objective regionalization only in terms of surface-wave velocities seems to be a better procedure than a priori classification in terms of more shallow structures and tectonic elements.

With respect to the mapping of local velocities, fig. 7a-f summarizes six examples, chosen from the $10-60 \mathrm{~s}$ period range. The main characteristics are the changes of local velocities detected throughout the Mediterranean basin.
The most remarkable feature is the strong N-S gradient detected on the eastern part, especially for 10, 20, 30 and $40 \mathrm{~s}$. Figures 8 and 9 show an example of local velocity uncertainties at $30 \mathrm{~s}$ and an example of resolving power for the same period, respectively. With respect to this last figure, it has to be emphasized that the highest resolving powers (poorly solved local velocities) are located in regions not densely covered by the set of epicentre-station paths. At the same time, the concept of resolving power helps us to define the elements (small cells of the basin) to be classified according to their group velocities. If we consider as reasonable values resolving powers less than $125 \mathrm{~km}$, we can define an averaged local group velocity for each cell of $1^{\circ}$ size. Consequently, the objective regionalization tries to classify into homogeneous groups only the cells associated with well solved local velocities. Cells linked to poorly solved areas are discarded for the regionalization process.

Table I illustrates the PCA results for our application. We can deduce a strong redundancy among the original variables because only three non-degenerated PC explain $94 \%$ of data variance. On the following regionalization procedure, the 46 group velocities belonging to the $10-60 \mathrm{~s}$ period range, associated with each cell, are substituted by the corresponding 3 factor scores (values of the $3 \mathrm{PC}$ at each cell).

Table II shows the evolution of the minimum value of the similarity index obtained along the AL process. We can easily detect a sharp increase when a fusion from 6 to 5 areas is attempted. Consequently, from the viewpoint of the local group velocities of Rayleigh waves fundamental mode, we can divide the Mediterranean basin into six homogeneous regions. The schematic distribution of these regions is depicted in fig. 10 , where areas designated $« 0$ » correspond to cells that have not been considered in the regionalization process. The classification obtained suggests, as maps of fig. 7 did, the possibility of remarkable structural variations.

Figure 11a-c depicts the group velocity dispersion curves linked to each homogeneous region. Squares and dashed lines represent the averaged group velocity and the corresponding 


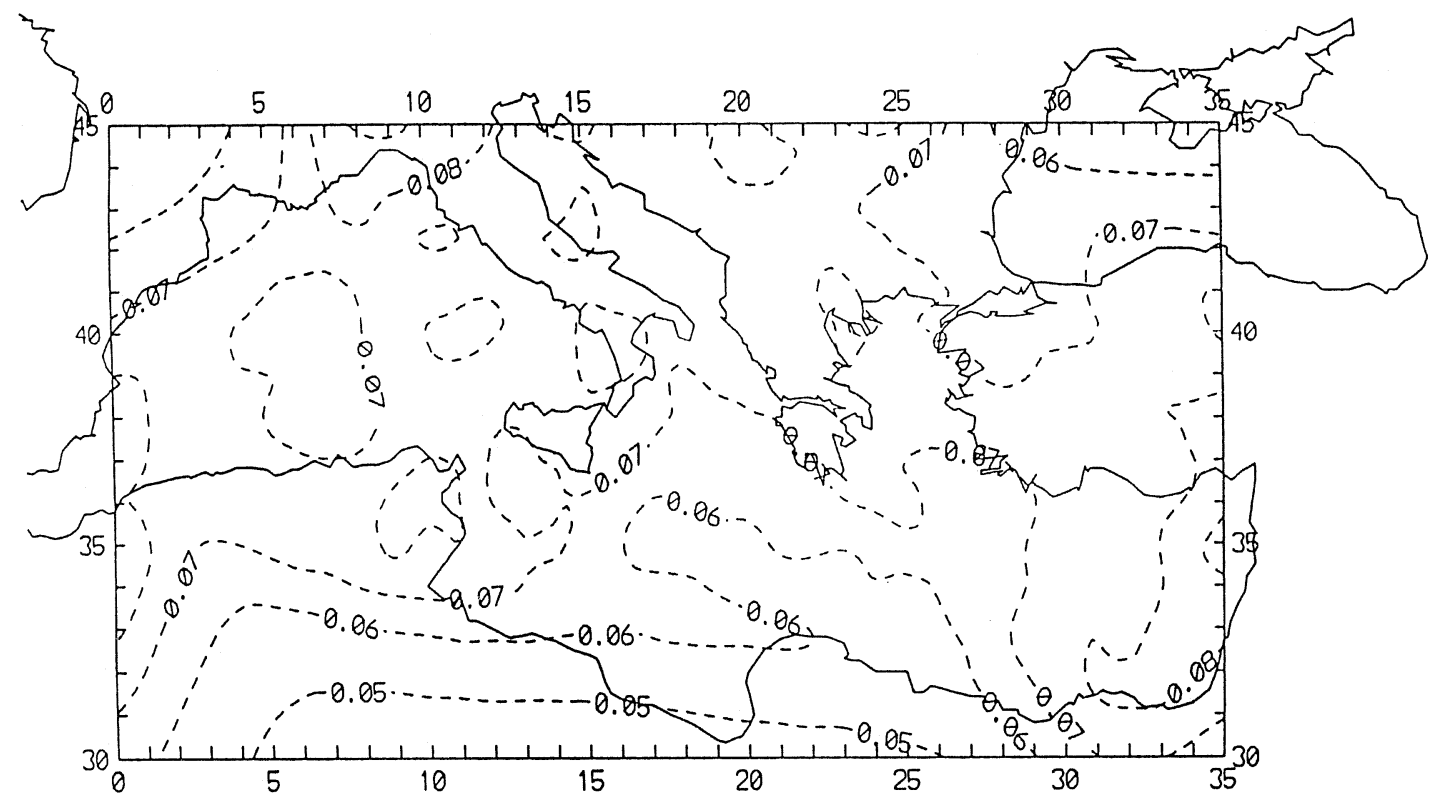

Fig. 8. Isolines of uncertainties $(\mathrm{km} / \mathrm{s})$ on local group velocities for a period of $30 \mathrm{~s}$.

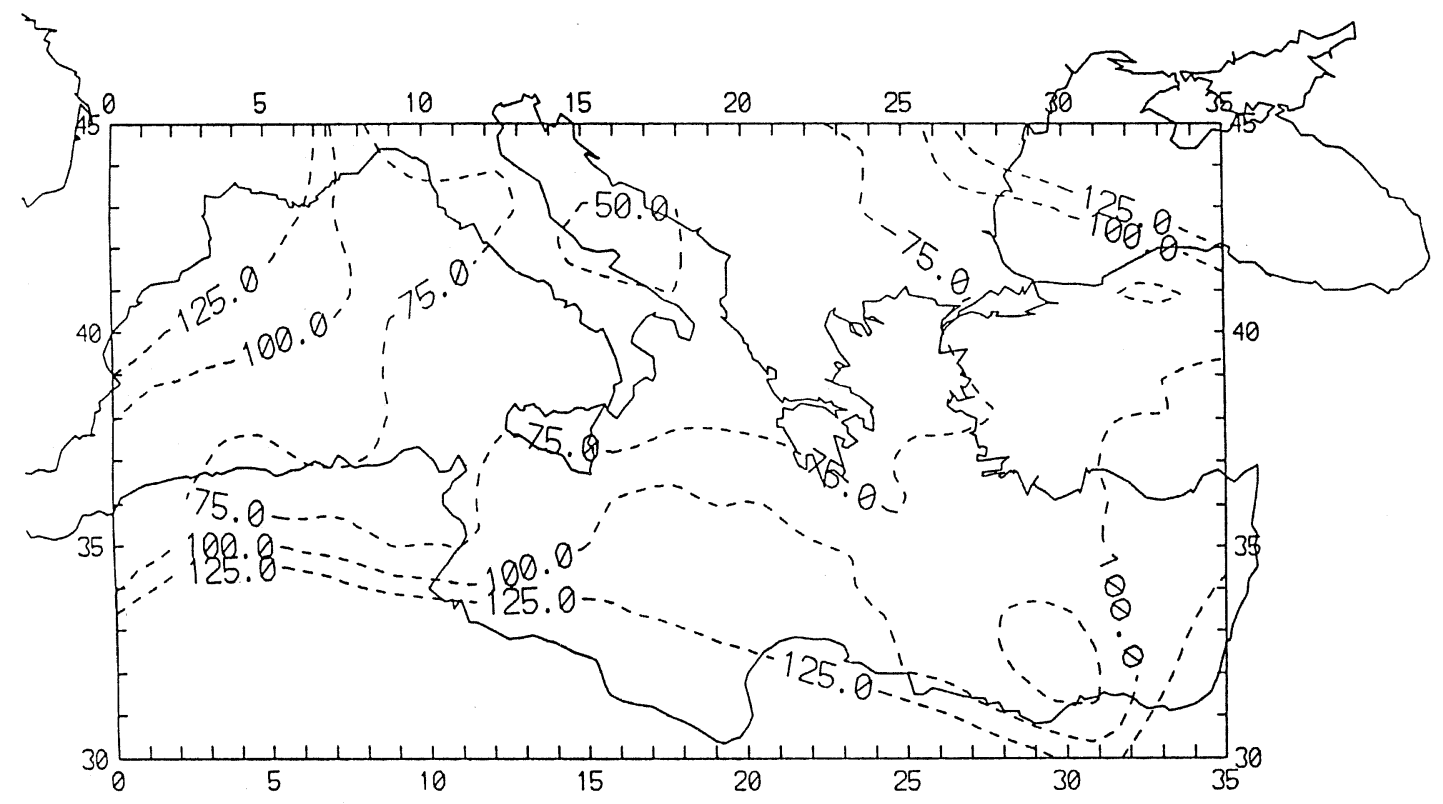

Fig. 9. Resolving power $(\mathrm{km})$ for a reference period of $30 \mathrm{~s}$. 
Table I. Principal components, explained variance and cumulative ratio of explained variance.

\begin{tabular}{ccc}
\hline $\begin{array}{c}\text { Principal } \\
\text { component }\end{array}$ & $\begin{array}{c}\text { Explained } \\
\text { variance }\end{array}$ & Ratio \\
\hline 1 & $\mathbf{3 2 . 2 3 4 5}$ & 0.7008 \\
2 & $\mathbf{9 . 1 5 1 9}$ & 0.8997 \\
3 & $\mathbf{1 . 9 1 2 8}$ & 0.9413 \\
4 & 0.9193 & 0.9613 \\
5 & 0.7269 & 0.9971 \\
6 & 0.3317 & 0.9843 \\
7 & 0.2237 & 0.9891 \\
8 & 0.1774 & 0.9930 \\
9 & 0.0736 & 0.9946 \\
10 & 0.0557 & 0.9958 \\
11 & 0.0424 & 0.9967 \\
$\ldots$ & $\ldots$ & $\ldots$ \\
44 & 0.0000 & 1.0000 \\
45 & 0.0000 & 1.0000 \\
46 & 0.0000 & 1.0000 \\
\hline
\end{tabular}

Table II. Evolution of the similarity index with the number of the remaining groups.

\begin{tabular}{cc}
\hline \hline Groups & $L(i, j)$ \\
\hline 19 & 1.3593 \\
18 & 1.4451 \\
17 & 1.4579 \\
16 & 1.4789 \\
15 & 1.4994 \\
14 & 1.5174 \\
13 & 1.5302 \\
12 & 1.5862 \\
11 & 1.7323 \\
10 & 2.2160 \\
9 & 2.4600 \\
8 & 2.8803 \\
7 & 3.0413 \\
6 & $\mathbf{3 . 2 2 8 0}$ \\
5 & 4.1882 \\
4 & 4.1902 \\
3 & 5.8382 \\
2 & 7.1531
\end{tabular}

error band for each period, respectively. Very remarkable differences can be observed, for instance, between regions 2 and 5 and regions 3 and 5 . On the contrary, the contiguous regions 1 and 2 show similar patterns, especially for periods greater than $20 \mathrm{~s}$.

The main characteristics of the six homogeneous regions are the following:

- Regions 1 and 2 correspond to the more active seismic area of the basin. The first one includes a SE-NW narrow band from the Egyptian coast to Greece. It is noteworthy that a part of the Aegean arc belongs to this region and the rest to the second one, which also includes much of Turkey. These regions are characterized by the lowest averaged group velocities, according to fig. 11a. Specifically, the area with the lowest local group velocities belongs to cluster 2 .

- Region 3 includes Tunisia, Sicily and part of the central basin. The seismicity in this area is more moderate than in the preceding ones and relevant activity is only detected in Sicily and the western part of the African coast. The averaged group velocities shown in fig. $11 \mathrm{~b}$ are greater than the corresponding values in regions 1 and 2 and smaller than velocities representing clusters 4 and 5 for periods less than 30-35 s.

- Region 4, delimited by zones number 1, 6 and 2 , forms a narrow band where the seismicity is relevant. It includes parts of ex-Yugoslavia, Bulgaria and Turkey. A small area, near the Alboran sea, also belongs to this cluster. The representative group velocities, together with those associated to clusters 5 and 6 , are the highest in the Mediterranean basin.

- Region 5 includes much of the Western Mediterranean basin and a small part of North Africa. The seismic activity is moderate in this area and the averaged group velocities obtained are higher than those corresponding to clusters 4 and 6 .

- Region 6 includes remarkable seismic areas as the Italian peninsula, the Adriatic area and a part of Bulgaria, Turkey and the Black sea. Some similarities on the averaged group velocities can be observed between regions 6 and 4 only from 20 to $50 \mathrm{~s}$.

- The remaining zones, indicated with 


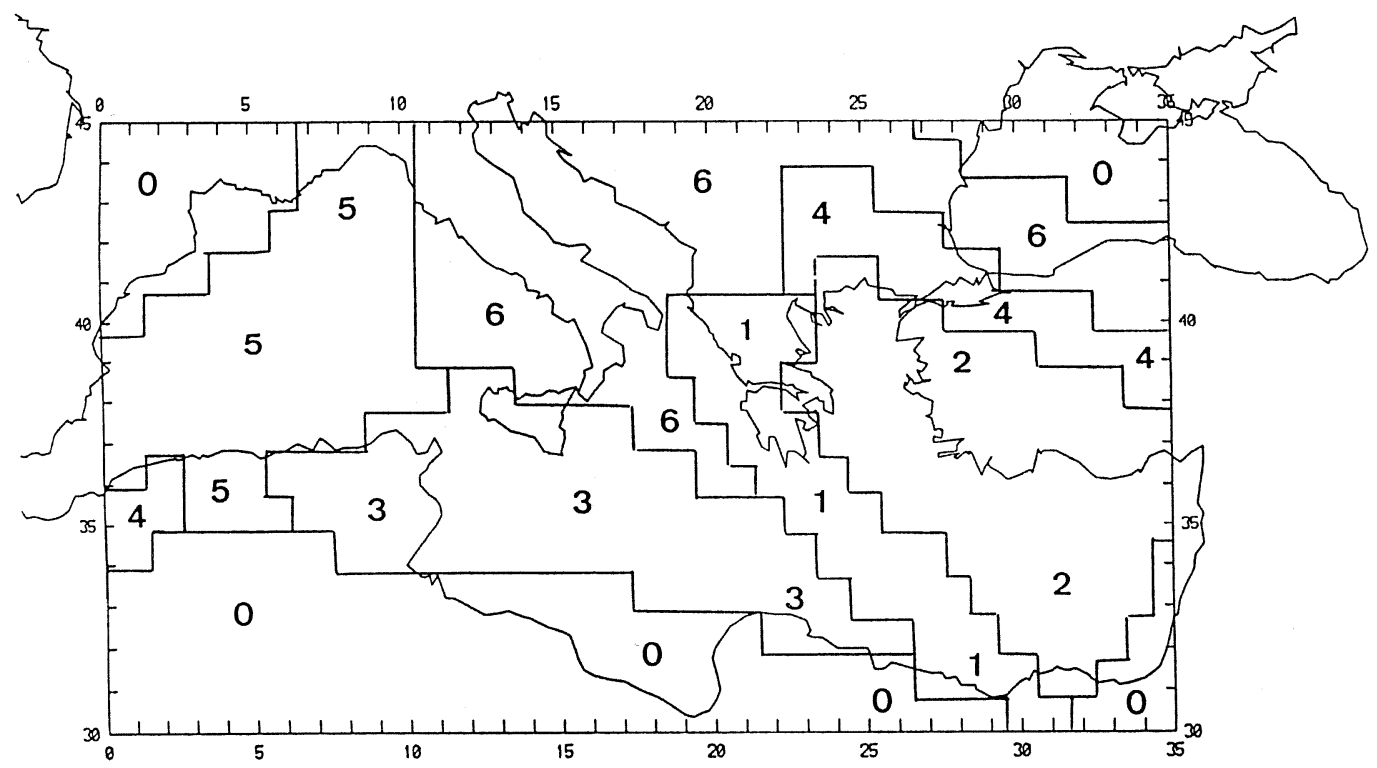

Fig. 10. Schematic description of the objective regionalization of the Mediterranean basin.

number 0 and discarded due to their low density of seismic paths and high resolving power, include alpine areas as the Pyrenees and a large part of the North Africa coast from Morocco to the Gulf of Sirte.

\section{Discussion and conclusions}

The results obtained up to now provide an objective regionalization of the Mediterranean basin in terms of local group velocities belonging to the fundamental mode of the Rayleigh waves, without a priori seismotectonic considerations. These results have to be completed in the near future by the application of inversion algorithms to the group velocity data to obtain shear velocity structures for each homogeneous region. Another interesting possibility consists of defining well solved local velocity groups (Nikolova et al., 1997) from maps computed at several periods. After that, we can obtain as many dispersion curves as well solved points on the maps. Posteriorly, a new application of the inversion algorithms will lead us to a more detailed description of the crust and upper mantle elastic structure of the Mediterranean basin.

An examination of local velocity maps suggests that lateral changes in the elastic structure have to be remarkable. Nevertheless, these lateral changes would have to be confirmed by the inversion of local dispersion curves. As an example, a transition from oceanic to continental structures is suggested by the strong velocity gradient for 10,20,30 and $40 \mathrm{~s}$ from the Egyptian coast to Turkey, affecting regions 2, 4 and 6 . Another interesting feature, perhaps the most remarkable, is the low local velocity area obtained for the SE end of the Mediterranean basin. The preliminary results in terms of shear $Q$ structure obtained by Rocamora et al. (1990) and the present local velocity determination may indicate the existence of a rifting process under the mentioned area. Another area that must be studied in depth from the viewpoint of the local velocities is region number 5 , which is formed in part of oceanic and in part of continental crustal structures according to other seismological data. 
(a)
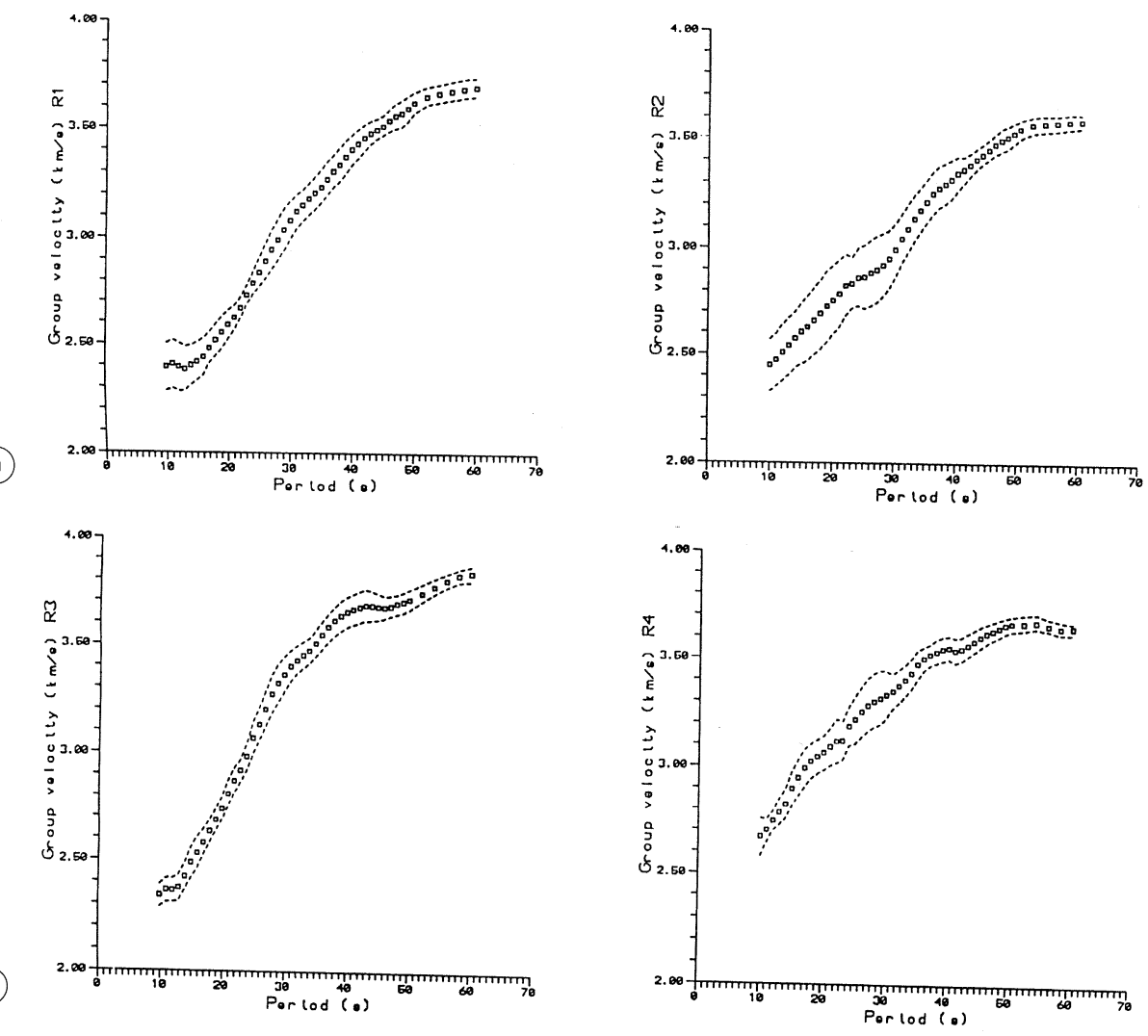

(b)
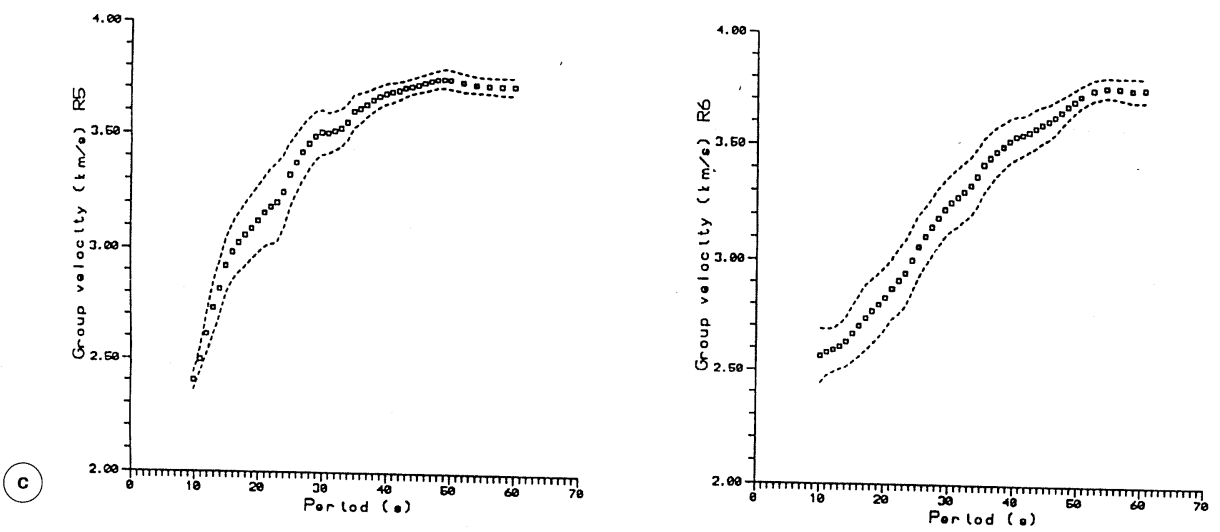

Fig. 11a-c. Averaged dispersion curves for (a) regions 1-2, (b) regions 3-4 and (c) regions 5-6. Open squares
design averaged group velocities for design averaged group velocities for each period. Dashed lines represent uncertainty bands on group velocities
for each period. 
Although the Iberian peninsula has been recently studied with the same methodology (Lana et al., 1997) and it has been possible to broadly link each region to a single tectonic area (Hercinic, Alpine or Neogene), it appears to be more difficult to establish this link in the present case. We have to bear in mind that the seismotectonic structure of the Iberian peninsula is less complex than those of the Mediterranean basin. An illustrative example is the Aegean arc, which does not form part of a single region but is shared by clusters 1 and 2 . The seismotectonic complexity of this highly active area has been discussed on the basis of seismicity features and stress pattern in the lithosphere (e.g. Papadopoulos et al., 1986). Possibly, linkages between seismotectonic areas and elastic structures will be obtained at a smaller scale after the systematic inversion of local dispersion curves.

Finally, we stress some aspects linked to the highest analyzed period and the improvement on the path coverage of the tomographic problem. Due to the dimensions of the Mediterranean basin, the analyzed periods can hardly ever exceed $70 \mathrm{~s}$ and in the near future we only can attempt a description of the crust, and possibly only the first kilometres beneath the asthenosphere. This relative shortcoming can be balanced by a very detailed description of the lateral changes of the elastic structure, which could be achieved by obtaining better resolving powers and smaller cells linked to well solved local velocities. This improvement implies obtaining a more dense path coverage. To this purpose, in the near future it is planned to add new seismic paths from teleseismic surface wavetrains recorded at pairs of stations located along the same great circle as the corresponding epicentre.

\section{Acknowledgements}

We would like to thank R. Console, A. Morelli, S. Mazza and other members of the Istituto Nazionale di Geofisica of Rome (Italy) for the facilities given to obtain data from the MEDNET network. This research was supported by the Dirección General de Investigación
Científica y Técnica (DGICYT), Projects PB920708 and PB93-0972. The present work fits into the Project titled Seismic Wave Velocity Structure on the Mediterranean and Black Sea Areas under supervision of the International Association for the Promotion of Cooperation with Scientists from the Independent States of the Former Soviet Union (Project INTAS93-92).

\section{REFERENCES}

BACKus, G. and F. GILBERT (1968): The resolving power of gross Earth data, Geophys. J. R. Astron. Soc., 16, 169-205.

BACKUS, G. and F. GILBERT (1970): Uniqueness in the inversion of inaccurate gross Earth data, Philos. Trans. R. Soc. Lon., Ser. A, 266, 123-192.

Banda, E., J. Ansorge, M. Boloix and D. CórdobA (1980): Structure of the crust and upper mantle beneath the Balearic Islands (Western Mediterranean), Earth Planet. Sci. Lett., 49, 219-230.

Banda, E., A. EgGer, M. Demartin, M. Maistrello and J. ANSORGE (1985): Crustal structure under Sardinia, in Second EGT Workshop. The Southern Segment (European Science Foundation, Strasbourg, France), 10-14.

BousqueT, J.C. and H. PhiliP (1986): Observations microtectoniques sur la compression nord-sud quaternaire des Cordillères Bétiques orientales (Espagne méridionale-Arc de Gibraltar, Bull. Soc. Géol. Fr., 3, 711-724.

CARA, M. (1973): Filtering dispersed wavetrains, Geophys. J. R. Astron. Soc., 33, 65-80.

DZIEWONSKI, A.M. (1984): Mapping the lower mantle: determination of lateral heterogeneities in $P$ velocity up to degree and order 6, J. Geophys. Res., 89, 59295952.

DZIEWONSKI, A.M. and A.L. HALES (1972): Numerical analysis of dispersive seismic waves, Meth. Comp. Physics, 11, 39-85.

FERnÁNDEZ Mills, G. and X. LANA (1994): Minimum sample size for synoptic weather type classification. Application to a winter period recorded at the Catalan coast (NE Spain), Inter. J. Climatol., 14, 1051-1060.

Fernández Mills, G., X. LANA and C. Serra (1994): Catalonian precipitation patterns: principal component analysis and automated regionalization, Theor. Appl. Climatology, 49, 201-212.

FinetTI, I. and G. Morelli (1972): Wide scale seismic digital exploration of the Mediterranean sea, Boll. Geofis. Teor. Appl., 14, 291-342.

Giardini, D., E. Boschi, S. Mazza, A. Morelli, D. BenSari, D. Najid, H. Benhallou, M. Bezzeghoud, H. Trabelshi, M. HFaidH, R.M. Kebeasy and E.M. IBRAHIM (1992): Very-broad-band seismology in Northern Africa under the MEDNET project, Tectonophysics, 209, 17-30. 
HATZFELD, D. (1978): Etude sismotectonique de la zone de collision Ibero-Magrebine, These Univ. Scient. Med. Grenoble, France.

HERRMANN, R.B. (1973): Some aspects of band-pass filtering of surface waves, Bull. Seism. Soc. Am., 63 (2), 663-671.

Kalkstein, C.S., G. TAN and J.R. Skindlov (1987): An evaluation of three clustering procedures for use in synoptic climatological classifications, J. Clim. Appl. Meteorol., 26, 717-730.

LANA, X. and R. CARBonell (1987): Surface harmonic expansion methodology in restricted domains of the Earth's surface: application to the Indian ocean, $J$. Geophys., 61, 158-167.

LANA, X. and G. Fernández Mills (1992): Local lithospheric stress distribution deduced by means of the total inversion algorithm and an objective classification method, Pure Appl. Geophys., 138 (3), 1-19.

Lana, X., G. Fernández Mills, J. Badal and J.A. CANAS (1997): Objective regionalization of rayleigh wave dispersion data by clustering algorithms, Geophys. J. Int. (in press).

MARTínEZ, M.D. and X. LANA (1991): Some elements of mathematical information theory and total inversion algorithm applied to a travel time inversion, Pure Appl. Geophys., 137 (1,2), 113-132.

McKenzIE, D. (1972): Active tectonics of the Mediterranean region, Geophys. J. R. Astron. Soc., 30, 109-185.

Michelini, A. and B.A. Bolt (1986): Application of the principal parameters method to the Coalinga, California, aftershock sequence, Bull. Seism. Soc. Am., 76, 409-420.

NAKANISHI, L. and D.L. ANDERSON (1982): Worldwide distribution of group velocity mantle Rayleigh waves as determined by spherical harmonic inversion, Bull. Seismol. Soc. Am., 72, 1185-1194.

Nikolova, S.B., J. BADAL and G. PAYO (1997): Local Rayleigh wave velocity dispersion in the Iberian region, Geophys. J. Int. (in press).

NishimurA, C.E. and D.W. FORSYTH (1985): Anomalous
Love waves phase velocity in the Pacific: sequential pure-path method and spherical harmonic inversion, Geophys. J. R. Astr. Soc., 81, 389-407.

NoRTH, G.R., T.L. BELL and R.F. CALAHAN (1992): Sampling errors in the estimation of empirical orthogonal functions, Month. Weather Rev., 110, 699-706.

Papadopoulus, G.A., D.P. Kondopoulou, G.A. LeVenTAKIS and S.B. PAVLIDES (1986): Seismotectonics of the Aegean region, Tectonophysics, 124, 67-84.

Periago, M.C., X. Lana, C. Serra and G. Fernández MILLS (1991): Precipitation regionalization: an application using a meteorological network in Catalonia (NE Spain), Int. J. Climat., 11, 529-543.

PHILIP, H. (1988): Recent and present tectonics in the Mediterranean region, in Seismic Hazard in Mediterranean Regions, edited by J. BoNNIN et al. (ECSC, EEC, EAEC, Brussels and Luxembourg), 283-300.

Posadas, A.M., F. Vidal, F. DE Miguel, G. Alguacil, J. PeÑa, J.M. IbAÑEZ and J. Morales (1993): Spatialtemporal analysis of a seismic series using the principal component method: the Antequera series, Spain, 1989, J. Geophys. Res., 98 (B2), 1923-1932.

Preisendorfer, R.W. (1988): Principal Component Analysis in Meteorology and Oceanography (Elsevier, Amsterdam, The Netherlands), pp. 455.

Rocamora, M., J.A. CANAS, L.G. Pujades, V. Corchete, J. BAdAl and G. PAYo (1990): Preliminary shear $Q$ structure in the Mediterranean sea from Rayleigh wave observations, J. Geodyn., 12, 177-187.

SATO, Y. and T. SANTO (1969): Worldwide distribution of the group velocity of the Rayleigh waves as determined by dispersion data, Bull. Earth. Res. Inst., 47, 31-41.

YANOVSKAYA, T.B. (1984): Solution of the inverse problem of seismology for laterally inhomogeneous media, Geophys. J. R. Astron. Soc., 79, 293-304.

YU, G.K. and B.J. MitCHELL (1979): Regionalized shear velocity models of the Pacific upper mantle from observed Love and Rayleigh wave dispersion, Geophys. J. R. Astron. Soc., 57, 311-341. 